\title{
An Application of the Theory of Planned Behavior to Predict the Intention and Practice of Nursing Staff Toward Physical Restraint Use in Long-Term Care Facilities: Structural Equation Modeling
}

This article was published in the following Dove Press journal:

Psychology Research and Behavior Management

Jun Wang (D)

Weichu Liu ${ }^{2}$

Qinghua Zhao (D)

Mingzhao Xiao ${ }^{3}$

Daomei Peng ${ }^{4}$

'Department of Nursing, The First Affiliated Hospital of Chongqing Medical University, Chongqing, People's Republic of China; ${ }^{2}$ Department of Gynecology,

The First Affiliated Hospital of Chongqing Medical University, Chongqing, People's Republic of China; ${ }^{3}$ Department of Urology, The First Affiliated Hospital of Chongqing Medical University, Chongqing, People's Republic of China;

${ }^{4}$ The First Social Welfare Home of Chongqing, Chongqing, People's Republic of China
Correspondence: Qinghua Zhao

I Youyi Road, Chongqing, 400016,

People's Republic of China

Tel +8618602308866

Fax +023-890I 2206

Email qh20063@163.com
Purpose: Understanding the factors that affect nursing staffs' intention and practice of physical restraint (PR) on older adults help develop restraint-reduction programs. This study aimed to identify the relationship between the Theory of Planned Behavior (TPB) constructs and nursing staffs' practice to use PR in long-term care (LTC) facilities.

Patients and Methods: A cross-sectional survey was conducted via convenience sampling among 316 nursing staff in six Chinese LTC facilities. PR-TPB questionnaire and the practice subscale of the Chinese version of the Staff Knowledge, Attitudes and Practices Questionnaire regarding PR were used to collect the data. Structural equation modeling (SEM) was used to examine the relationship between variables.

Results: The SEM fit well with the data $\left(\chi^{2} / d f=1.639, R M S E A=0.045, \mathrm{CFI}=0.955\right.$, GFI $=0.945)$. Attitude $(\beta=0.536, \quad P<0.001)$ and perceived behavioral control (PBC) $(\beta=0.139, P<0.05)$ predicted intention $\left(R^{2}=0.359\right)$. PBC was a significant predictor of practice, with $R^{2}$ accounting for 0.151 .

Conclusion: TPB provided useful insight into better understanding nursing staffs' PR practices, although it did not support all the TPB principles significantly. Prospective studies may be conducted to design and implement multi-component interventions based on TPB and explore the effectiveness of PR reduction in LTC facilities in-depth.

Keywords: physical restraints, nursing home, aged, the theory of planned behavior, nursing, China

\section{Introduction}

2020 world population data sheet shows older populations growing, and fertility rates declining. ${ }^{1}$ Almost every country is facing the challenges of an aging population. In China, by the end of 2019, the population aged $60+$ had reached 254 million, and the population aged 65+ had reached 176 million, accounting for $18.1 \%$ and $12.6 \%$ of the total population, respectively. ${ }^{2}$ Due to the aging pattern of more disabilities, venerable ages, empty nests and fewer young adults in China, to satisfy the multiple needs of health care for older adults, the long-term care (LTC) facilities have developed rapidly. More and more older adults are choosing to live in LTC facilities. Improving and ensuring older adults' LTC quality has become a vital issue in geriatric care. ${ }^{3}$ As an important quality indicator in the nursing care process, physical restraint (PR) has been receiving more and more attention. ${ }^{4}$ 
PR is defined as

Any action or procedure that prevents a person's free body movement to a position of choice and/or normal access to their body by using any method that is attached or adjacent to a person's body and that they cannot control or remove easily. ${ }^{5}$

Some previous studies have proved that PR is connected with numerous adverse consequences on the physical (eg, pressure ulcer, infection, deep vein thrombosis, malnutrition, etc.), mental (eg, fear, loneliness, anger, depression, etc.), and social (eg, isolation, low social value, low self-esteem, behavioral disorder, etc.) state of older adults even causing accidental death. ${ }^{6-8}$ Moreover, there is no clear evidence showing the effectiveness of PR in preventing accidental injuries or protecting older adults' safety. ${ }^{9,10}$ Even then, PR is commonly used in LTC facilities, with usage rates ranging from $6 \%$ to $84.9 \%{ }^{3,11,12}$

A large number of studies have shown that the characteristics of older adults, such as advanced age, care dependency, cognitive impairment, mobility restriction, fall risk, physical agitation, indwelling tubes, etc., are essential factors that contribute to using PR in LTC facilities. ${ }^{11-15}$ Organizational characteristics such as type and ownership of facilities, nursing staff levels, regulations, and PR policies, etc. are also vital factors. ${ }^{16,17}$ Other than this, the family also plays an important role in the use of PR. Some studies have suggested that relatives' or families' participation in decision-making and communicating with them could reduce the PR use in LTC environments. ${ }^{18,19}$ A study on home care revealed that high family support perceived by informal caregivers led to lesser use of PR. ${ }^{20}$

Decisions and practice processes about using PR are complicated and affected by various factors. ${ }^{21}$ In LTC facilities, the practice of PR, such as alternatives to restraints, type of restraint, time to release/loosen restraint, informed consent and the care of restrained older adults, is usually determined by nursing staff based on their evaluation and care experience for older adults. ${ }^{22}$ Namely, nursing staff are the primary performers and decision-makers of PR use in LTC facilities. Therefore, nursing staffs' knowledge and attitude are frequently mentioned as one of the most powerful determinants of restraint use. ${ }^{23,24}$ Therefore, it is recommended to adopt a theoretical framework to explore the socio-cognitive factors affecting the nursing practice of $\mathrm{PR}^{25}$ For instance, Werner et al in Israel applied the Theory of Reasoned Action (TRA) to demonstrate nursing staffs' intention to use PR on older adults. ${ }^{26}$ Lately, ViaClavero et al conducted a series of Theory of Planned Behavior (TPB) based studies, (a) eliciting intensive care unit (ICU) nurses' beliefs regarding the use of PR, (b) developing PR-TPB questionnaire to evaluate nurses' intention toward PR on intubated patients in ICU and (c) detect that TPB model accounts for $33 \%$ of the variance in intention. ${ }^{25,27,28}$ Studies on LTC facilities from the perspective of PR practitioners focus on the investigation of knowledge, attitudes, practice, and experience. They rarely use a complete theoretical framework to understand social norms, staff interactions, intention in the process of PR use by nursing staff. Thus, a social behavior theory like TPB probably is probably a better tool for analyzing psychosocial factors of PR use as it offers a commonly used and concise model to explain human-related behavior.

TPB, developed by Ajzen, is a behavioral theory in social psychology that analyzes factors affecting behavioral intentions and explains behavior. ${ }^{29}$ It pointed out that the main factor in predicting behavior is changing behavioral intentions, which depends on (a) attitude, positive or negative evaluation of the individual of specific behavior, (b) subjective norm (SN), the social pressure an individual perceives from other individuals or groups about adopting a specific behavior and (c) perceived behavioral control (PBC), the control ability an individual perceives to perform a specific behavior. TPB is frequently used to develop behavioral intention assessment instruments and predict various behaviors, especially regarding the influence of personal, psychological and social factors. ${ }^{30-33}$ Moreover, TPB was also widely used in designing various behavioral interventions, for instance, a multicomponent restraint-reduction intervention based on TPB was developed and implemented in German nursing homes. ${ }^{34}$ However, variables under the TPB constructs do not always significantly contribute to the practice for every behavior or every population. ${ }^{35,36}$ Whether a variable plays a significant role in the intention, adopting the behavior depends on the behavioral patterns evaluated and the aimed samples. ${ }^{37}$

We conducted a bibliometric study of literature from four databases (Pubmed, CINAHL, EMBASE, Cochrane library), that reported studies regarding PR in LTC facilities mainly focus on (a) impact of PR on older adults, (b) perspective and experience of stakeholders (nursing staff, older adults, families/relatives, etc.), (c) the uses of PR and its influencing factors and (d) restraint-reduction interventions. ${ }^{38}$ Most of these publications were from developed countries and regions with well-established elderly 
welfare systems, such as the USA, Germany, Netherlands, Canada, etc. However, studies about PR use in LTC facilities lack in China, especially in the Chinese mainland. ${ }^{38}$ Such developing regions with a fast-aging population and less experience of coping with aging make that it is difficult to directly learn from the experience of countries with great welfare systems. Therefore, it is necessary to develop restraint-reduction interventions that match our native cultures and social backgrounds. Additionally, accepting that TPB can adequately explain variance in PR has yet to be validated among the nursing staff in China. Yet, it is obvious that influencing nursing staffs' practice of PR demands know how of socio-cognitive factors that affect their decision-making. Thus, this study aims to report nursing staffs' intention and practice toward PR use in LTC facilities and to determine whether the TPB constructs predict this practice. This could provide a fundamental basis to support the development of targeted interventions such as education programs and multicomponent restraint-reduction projects.

The theoretical framework of this study was formed per the TPB (Figure 1). We assumed that (a) nursing practice toward PR use is affected by intention and PBC, (b) attitude, SN and PBC are intercorrelated and (c) they have a direct influence on nursing staffs' intention toward PR in LTC facilities.

\section{Patients and Methods}

\section{Study Design, Sample and Setting}

A cross-sectional survey was conducted in six LTC facilities selected via convenience sampling in Chongqing, China.
A cluster sample of the nursing staff was chosen from these six facilities from November to December in 2019 and May to June in 2020. The gap in the data collection was due to the COVID-19 epidemic. Inclusion criteria: all nurses and nursing assistants who practiced the closest care to older adults in the facilities. Exclusion criteria: nursing staff (a) who were not engaged in clinical practice (eg only with managerial position), (b) who were informal staff such as interns and rotations staff, and (c) who were hired as regular staff with less than 12 months of clinical practice. Based on sample size estimation of structural equation model (SEM) analysis, ${ }^{39}$ samples need to be larger than 10 times the number of estimated parameters. Our study sample of 316 nursing staff satisfied the requirements.

There were nearly 1200 beds in the six LTC facilities. Of these facilities, four were nursing homes, one social welfare, and one aged care center. We had previously investigated characteristics of the LTC facilities and older adults, and analyzed organizational and individual factors affecting PR use in these six places. ${ }^{16}$ Three LTC facilities have units with in-house standards for PR and four have dementia care units. Older adults in four LTC facilities required families' informed consent before using PR. Older adults per nurse and older adults per nursing assistant were $30.95(\mathrm{SD}=9.99)$ and $5.64(\mathrm{SD}=3.27)$, respectively. The prevalence of older adults with at least one PR was $25.83 \%$ (265/1026). 92.50\% (949/1026) older adults had moderate to high-level risk of fall and $42.20 \%$ (443/ 1026) were in moderately to severely impairment group. Over half of older adults had moderate to severe care dependency. The rate of antipsychotics use was $19.10 \%$.

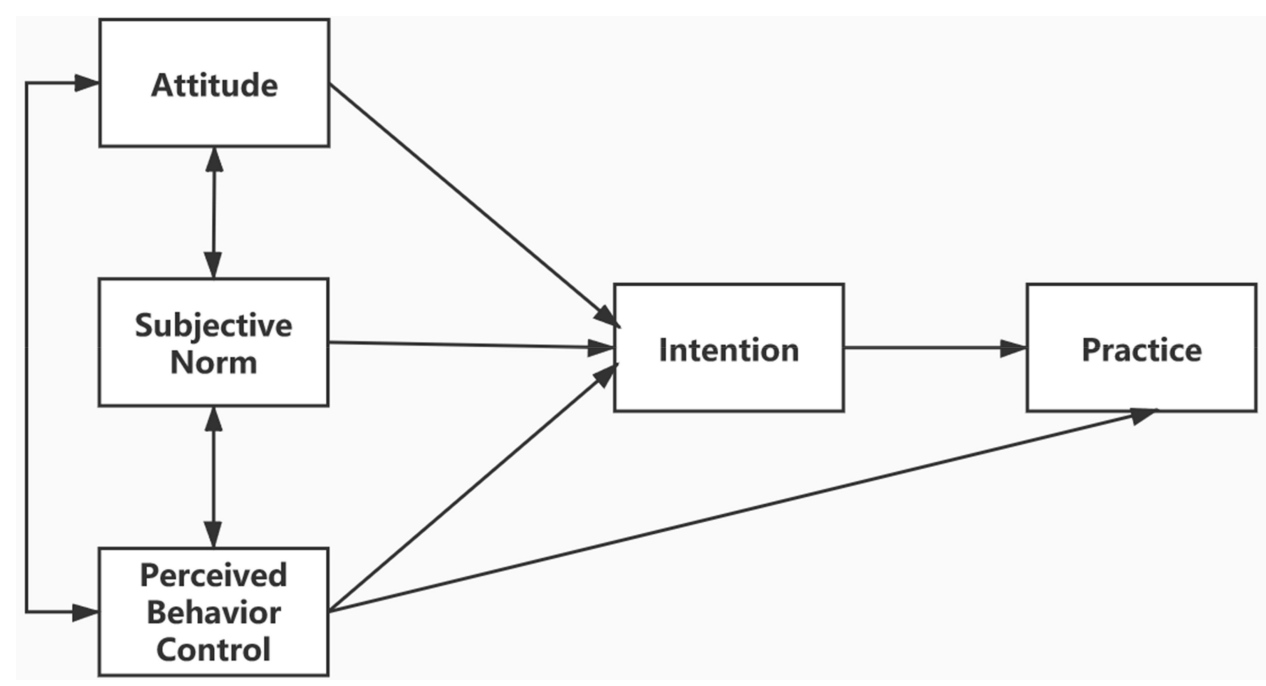

Figure I The conceptual model of this study. 


\section{Measurements}

Reflective (“direct") measures of attitude, SN and PBC were recommended to predict intentions and behaviors, ${ }^{40}$ SN emphasizes the influence of "important people", however, direct measures of SN are general items, such as "People who are important to me would disapprove/ approve of my practice of PR". The information on how various "important people" specifically affect nursing staff could not be obtained from direct items. Meanwhile, studies revealed that stakeholders in the process of PR use such as doctors, nurses/nursing assistants, older adults/ their relatives may hold different views, thereby, nursing staff perceived different social pressure, even opposite. ${ }^{23,41}$ So indirect reliefs were developed to measure $\mathrm{SN}$ in this study, which had been applied in other studies. ${ }^{26,36,42}$ The Physical Restraint Theory of Planned Behavior (PR-TPB) questionnaire based on Ajzen's TPB ${ }^{40}$ was developed earlier in the following three stages (Journal of Nurses Training, unpublished yet).

Stage 1-The initial item pool was formed through (a) literature review related to the $\mathrm{TPB}^{26,27}$ and (b) results of a qualitative study we conducted using an open-ended questionnaire $(\mathrm{n}=20)$ and semi-structured interview $(n=12) .{ }^{22}$ From the results of this study, we (a) generated items of SN, (b) supplement items of attitude in the context of Chinese culture, and (c) determined intention to use $\mathrm{PR}$ in five hypothetical situations based on the most frequent reasons for using PR in Chinese LTC facilities. Then, a 21-item PR-TPB draft questionnaire was formed that included attitude (5 items), SN (7 items), PBC (4 items) and intention (5 items), with each answer's visual score ranging from 1 to 7 points.

Stage 2-Ten experts with relevant research experience or clinical practice in TPB, geriatric care, physical restraint, and scale development were invited to assess the content validity index (CVI) of the questionnaire. According to their feedback, each item-level CVI (I-CVI) of the questionnaire was between 0.80 and 1.00 , and the scale-level CVI (S-CVI) was 0.95, which indicated good content validity for the questionnaire. ${ }^{43}$ Moreover, the questionnaire was piloted with 30 randomly selected nursing staffs. This was to test the clarity, readability and intelligibility of the items. Based on the participants' feedback, minor language descriptions were modified, and the visual scoring (1 to 7) method was replaced with the 7-point Likert scoring method. No items were deleted in the above stages.
Stage 3-Data of 316 nursing staff members were used to identify the reliability (consistency of this measure) and validity (accuracy of this measure) of the questionnaire. Discrimination ability was used by the Pearson's correlation coefficients between item and its subscales and five items were removed due to correlation coefficients which were below 0.30 or insignificant $(P>0.05) .{ }^{44}$ The construct validity was assessed by exploratory factor analysis (EFA) and confirmatory factor analysis (CFA). ${ }^{44}$ One item was removed in the EFA stage and the final cumulative contribution of variance was $57.277 \%$, which is in an acceptable range. CFA accomplished by AMOS showed a good fit with data, $\chi^{2} / d f=1.428$, root mean square error of approximation (RMSEA) $=0.037$, goodness-of-fit index $(\mathrm{GFI})=0.961$, adjusted goodness of fit index (AGFI) $=0.933$, comparative fit index $(\mathrm{CFI})=0.976, \mathrm{NFI}=0.926$, incremental fit index (IFI) $=0.977$. The reliability was assessed by internal consistency reliability and test-retest reliability. ${ }^{44}$ The Cronbach's $\alpha$ coefficient for total questionnaire was 0.783 and that for the four dimensions (attitude, SN, PBC and intention) were 0.651, 0.721, 0.815 and 0.638 , respectively. According to the recommended level of a coefficient's alpha $\geq 0.70$ of the total questionnaire and $\geq 0.60$ of subscales, ${ }^{45}$ the final questionnaire showed adequate reliability. Additionally, the Pearson's correlation coefficients for test-retest reliability $(\mathrm{n}=30)$ for the total questionnaire, attitude, SN, PBC and intention were $0.845,0.827,0.768,0.918$ and 0.798 , respectively, which indicated acceptable stability $(r>$ 0.70) over 2-week period. The final PR-TPB questionnaire contained four scales and 15 items.

Attitude toward PR use was measured with four opposing adjectives, including unsafe/safe, unnecessary/necessary, harmful/beneficial and unaccepted/accepted. For example, I think that using physical restraints in older adults is $1=$ extremely unsafe, $2=$ quite unsafe, $3=$ slightly unsafe, $4=$ neither, $5=$ slightly safe, $6=$ quite safe, $7=$ extremely safe. The total score ranged from 4 to 28 , and the higher scores indicated more positive attitudes.

SN was measured with five items included the following social referents: co-workers (nursing staff), doctors, nursing administrator, family members, and older adults (ie, Family members supported PR use on older adults, my perspective is: $1=$ strongly disagree to $7=$ strongly agree). The total score ranged from 5 to 35 . The higher scores indicated the more support of social referents support to PR. 
PBC was measured with three items: i) I could use physical restraints on older adults if I felt it is necessary; ii) It is easy for me to decide to use physical restraints on older adults; iii) The decision to use physical restraints on older adults is up to me. Each item was scored from $1=$ strongly disagree to $7=$ strongly agree. $\mathrm{PBC}$ score ranged from 3 to 21. Higher scores indicated higher confidence and ease of PR use.

Intention has measured the use of PR in three hypothetical situations (wandering, fall, and feeding tube). A 7 -point answer $(1=$ definitely not use to $7=$ definitely use) was used to assess intention to use PR in each specific situation. The total score of intention ranged from 3 to 21 . The higher scores reported a high intention to use PR.

The practice was measured using practice subscale of the Chinese version of the Staff Knowledge, Attitudes, and Practices Questionnaire regarding PR, which was validated by Suen. ${ }^{46}$ The practice subscale included 14 items in restraint use, such as issues about the use of alternatives before restraining, informed consent, removal of restraint, the care of restrained older adults, etc. Each item was scored ranging from 1 (never) to 3 (always). The total score (14 to 42) was computed by summing up all items. Higher scores indicated the more standard practice of PR. The Pearson's correlation coefficient for test-retest reliability after two weeks ( $\mathrm{n}=30)$ was 0.915 . The Cronbach's $\alpha$ coefficient was 0.800 .

Demographic characteristics contained age, gender, ethnic group, marriage, education, income, job title, work shifts, religion, years of geriatric care practice, and in-job training on PR including training times and form.

\section{Data Collection}

This study was conducted in accordance with the Declaration of Helsinki and approved by the ethics committee of the First Affiliated Hospital of Chongqing Medical University (No: 2019-104). We contacted the person in charge of the facilities in advance, and after getting permission, the person in charge lead the investigators to conduct the investigation. The investigation team consisted of 2 postgraduate students and 2 undergraduate students. Data collectors received training on investigation methods and procedures. Simulation training was also conducted for uniform data collection. During the investigation, the nursing staff was asked for consent and then the paper questionnaires were distributed one-on-one, filled out and collected on the spot. The investigators conducted questionnaires on a one-on-one, face-to-face interview with the nursing staff who were at lower education level without any hint and guidance. After participants completed the questionnaires, the information was reviewed and confirmed on the spot.

\section{Data Analysis}

EpiData 3.1 software was used to double input all data and analyzed using SPSS 25.0 software. A descriptive analysis of the variables was using rate, means and standard deviations (SD). The correlation analysis between the variables was done using Pearson's linear correlation. After a model was established using AMOS version 23.0, parameter estimation was performed using maximum likelihood estimation, and the model was optimized according to the larger correction index. Model fitting with a Chi-square value/ degrees of freedom ratio $\left(\chi^{2} / d f\right)<3.0$, RMSEA $<0.07,{ }^{47} \mathrm{GFI}$, IFI, AGFI, and CFI of 0.90 or above are usually regarded as an indication of good coordination. ${ }^{48}$ If the above requirements are met, the fitting of the model is considered acceptable A two-tailed a-value of 0.05 was set for significance.

\section{Results}

\section{Demographic Characteristics of Nursing Staff}

All 350 nursing staff members from in the six LTC facilities were invited to participate in the study, out of which 316 completed the questionnaire with an effective response rate of $90.28 \%$. The participants had a mean age of 43.52 years $(S D=10.06)$. Of the 316 participants, $216(68.30 \%)$ were female. Two hundred and sixty-two (82.91\%) were married and 215 (68.04\%) had a middle school education level or below. The mean duration of clinical geriatric care experience was 3.81 years $(S D=2.10)$ and 203 (64.24\%) had accepted in-job training on PR use (informal, 1-2 times/year, 10-20 minutes/time). Of all the participants, 247 (78.2\%) were nursing assistants. See more details in Table 1.

\section{Descriptive Analysis}

Table 2 shows the means and standard deviations of the TPB questionnaire and practice for PR use. The mean total score of the items on nursing practice was $30.89(S D=4.82)$, ranging from 20 to 38. The mean score of the attitude, SN, PBC and intention was $5.30(S D=0.62), 4.55(S D=0.73), 3.99$ $(S D=1.31), 5.05(S D=0.88)$, respectively. The mean score for each item attitude was over 5.00 points, showing a relatively positive attitude toward the use of PR by nursing 
Table I Sample Characteristics $(n=316)$

\begin{tabular}{|c|c|c|c|}
\hline Variables & Category & $\mathbf{n}$ & $\%$ \\
\hline \multirow[t]{2}{*}{ Gender } & Male & 100 & 31.65 \\
\hline & Female & 216 & 68.35 \\
\hline \multirow[t]{2}{*}{ Ethnic group } & Han nationality & 293 & 92.72 \\
\hline & National minority & 23 & 7.28 \\
\hline \multirow[t]{2}{*}{ Job title } & Nurses & 69 & 21.84 \\
\hline & Nursing assistants & 247 & 78.16 \\
\hline \multirow[t]{3}{*}{ Marriage } & Married & 262 & 82.91 \\
\hline & Unmarried & 33 & 10.44 \\
\hline & Others & 21 & 6.65 \\
\hline \multirow[t]{4}{*}{ Education } & $\begin{array}{l}\text { Primary school } \\
\text { and below }\end{array}$ & 76 & 24.05 \\
\hline & Middle school & 139 & 43.99 \\
\hline & High school & 36 & 11.39 \\
\hline & $\begin{array}{l}\text { Undergraduate } \\
\text { and above }\end{array}$ & 65 & 20.57 \\
\hline \multirow[t]{4}{*}{ Income per month (RMB, Yuan) } & $2000 \sim 3000$ & 38 & 12.03 \\
\hline & $300 \mathrm{I} \sim 4000$ & 174 & 55.06 \\
\hline & $400 \mathrm{I} \sim 5000$ & 93 & 29.43 \\
\hline & $>5001$ & 11 & 3.48 \\
\hline \multirow[t]{2}{*}{ Religion } & Yes & 13 & 4.11 \\
\hline & No & 303 & 95.89 \\
\hline \multirow[t]{3}{*}{ Work shifts } & Days & 44 & 13.92 \\
\hline & Day-night in turn & 182 & 57.59 \\
\hline & 24 hours & 90 & 28.48 \\
\hline \multirow{2}{*}{$\begin{array}{l}\text { Receive in-school training on } \\
\text { physical restraint }\end{array}$} & Yes & 58 & 18.35 \\
\hline & No & 258 & 81.65 \\
\hline \multirow{2}{*}{$\begin{array}{l}\text { Receive in-job training on } \\
\text { physical restraint }\end{array}$} & $Y_{e s}{ }^{a}$ & 203 & 64.24 \\
\hline & No & 113 & 35.76 \\
\hline
\end{tabular}

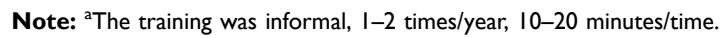

staff. Nursing staff believed that other co-workers (mean=5.05, $\mathrm{SD}=0.96)$, doctors (mean=4.96, $\mathrm{SD}=0.94)$ and families (mean=4.37, $\mathrm{SD}=1.17$ ) would approve of them using PR, but the older adults (mean=3.59, $\mathrm{SD}=1.20$ ) would not. The study demonstrated that nursing staff had moderate self-efficacy (mean $=4.40, \mathrm{SD}=1.47$ ) and ease (mean=4.01, $\mathrm{SD}=1.51$ ) of $\mathrm{PR}$ use, though their confidence (mean=3.56, $\mathrm{SD}=1.61$ ) was weak. They showed more intention to use PR with the feeding tubes (mean $=5.94, \mathrm{SD}=0.88$ ) and falls (mean=4.90, $\mathrm{SD}=1.22$ ).

\section{Correlations of Study Variables}

Correlation analyses between the variables in SEM are presented in Table 3. The study demonstrated that the attitude, SN and $\mathrm{PBC}$ had significant positive correlations with intention $(r>0, P<0.05)$. Moreover, the attitude, $\mathrm{SN}$, $\mathrm{PBC}$ and intention were negatively associated with nursing practice $(r<0, P<0.05)$.

\section{Structural Equation Modeling}

Based on the conceptual model (Figure 1) and correlation analysis results, we conducted an SEM to test whether the TPB model was consistent with the variable correlations. We optimized the model based on modification indices. Finally, the model-fit indices were as follows: $\chi^{2} / d f$ $=147.554 / 90=1.639, \quad R M S E A=0.045 \quad[95 \%$ CI $\quad(0.031$, 0.048)], GFI $=0.945, \mathrm{CFI}=0.955, \mathrm{IFI}=0.956, \mathrm{AGFI}=0.917$, indicating the model fit well with the data.

According to the final model path (Figure 2), stronger attitude $(\beta=0.536, P<0.001)$, $\mathrm{PBC}(\beta=0.139, P<0.05)$ were all related to stronger intention. Stronger SN was also related to the stronger intention, however, the path coefficient had no statistical significance $(\beta=0.046, P=0.646$ ). Regarding the nursing practice, $\mathrm{PBC}$ displayed a negative direct effect $(\beta=-0.348, \quad P<0.001)$ on it, but intention was not a significant predictor of practice $(\beta=-0.117, P=0.057)$. Based on the $R^{2}$ values, the final model accounted for $35.9 \%$ and $15.1 \%$ of the variance in intention and practice, respectively. See effect correlation coefficients from Table 4.

\section{Discussion}

\section{The Score Status of the Variables}

The nursing staff in this study reported moderate levels of PR practice on older adults, which indicated the standardized practice of PR could be further improved. When compared, our study scored a lower nursing practice score of than that in the study of Kor et al in Hong Kong and Karagozoglu et al in Turkey but higher than that of Eskandari et al in Malaysia. ${ }^{24,49,50}$ Such dissimilarities could be explained by regional and cultural differences, PR practice management, restraint education programs, etc. For instance, over the past two decades, the "minimized restraint" guideline was adopted by Hong Kong Social Welfare Department, making restraint- 
Table 2 Mean and Standard Deviation of the Score for the Variables

\begin{tabular}{|c|c|c|c|c|c|c|}
\hline \multirow[t]{2}{*}{ Variables } & \multicolumn{2}{|c|}{ All Participants } & \multicolumn{2}{|c|}{ Nurses } & \multicolumn{2}{|c|}{ Nursing Assistants } \\
\hline & Mean & SD & Mean & SD & Mean & SD \\
\hline Attitude & 5.30 & 0.62 & 5.14 & 0.81 & 5.34 & 0.55 \\
\hline Attitude I Unsafe/safe & 5.24 & 0.85 & 5.10 & 0.83 & 5.28 & 0.85 \\
\hline Attitude 2 Unnecessary/necessary & 5.44 & 0.94 & 5.22 & 1.12 & 5.50 & 0.87 \\
\hline Attitude 3 Harmful/beneficial & 5.33 & 0.84 & 5.13 & 1.06 & 5.39 & 0.76 \\
\hline Attitude 4 Unacceptable/acceptable & 5.17 & 0.92 & 5.12 & 1.09 & 5.18 & 0.86 \\
\hline Subjective norm (SN) & 4.55 & 0.73 & 4.52 & $0.8 I$ & 4.56 & 0.71 \\
\hline SN I Co-workers (nursing staff) & 5.05 & 0.96 & 5.06 & 1.08 & 5.04 & 0.92 \\
\hline SN 2 Doctors & 4.96 & 0.94 & 5.12 & 0.96 & 4.91 & 0.93 \\
\hline SN 3 Nursing administer & 4.79 & 1.02 & 4.96 & 1.16 & 4.74 & 0.98 \\
\hline SN 4 Family members & 4.37 & 1.17 & 4.14 & 1.25 & 4.44 & 1.13 \\
\hline SN 5 Older adults & 3.59 & 1.20 & 3.30 & 1.14 & 3.68 & 1.21 \\
\hline Perceived behavioral control (PBC) & 3.99 & 1.31 & 3.42 & 1.48 & 4.15 & 1.21 \\
\hline PBC I Self-efficacy of PR use & 4.40 & 1.47 & 3.87 & 1.61 & 4.54 & 1.40 \\
\hline PBC 2 Ease of PR use & 4.01 & 1.51 & 3.48 & 1.59 & 4.16 & 1.45 \\
\hline PBC 3 Confidence of PR use & 3.56 & 1.61 & 2.91 & 1.83 & 3.74 & 1.50 \\
\hline Intention & 5.05 & 0.88 & 4.90 & 0.92 & 5.10 & 0.87 \\
\hline Intention I Wandering & 4.32 & 1.32 & 4.12 & 1.38 & 4.38 & 1.30 \\
\hline Intention 2 Fall risk & 4.90 & 1.22 & 4.65 & 1.35 & 4.97 & 1.18 \\
\hline Intention 3 Feeding tubes & 5.94 & 0.88 & 5.94 & 0.76 & 5.94 & 0.91 \\
\hline Nursing practice & 30.89 & 4.82 & 34.59 & 3.75 & 29.86 & 4.58 \\
\hline
\end{tabular}

reduction training requirement. Following this, nursing staffs' practice of using PR in Hong Kong (2018) reported a significant improvement compared with a similar local study (1999). ${ }^{49}$ Although nearly two-thirds of the nursing

Table 3 Correlations Between Measured Variables Used in the SEM

\begin{tabular}{|l|l|l|l|l|}
\hline Variables & Attitude & SN & PBC & Intention \\
\hline SN & $0.460^{* *}$ & & & \\
\hline PBC & $0.126^{*}$ & $0.144^{*}$ & & \\
\hline Intention & $0.387^{* *}$ & $0.340^{* *}$ & $0.249 * *$ & \\
\hline Practice & $-0.215^{* *}$ & $-0.155^{* *}$ & $-0.362^{* *}$ & $-0.169 * *$ \\
\hline
\end{tabular}

Notes: $* * P<0.001, * P<0.05$.

Abbreviations: SN, subjective norm; PBC, perceived behavioral control. staff in this study had received training on PR use, the training itself was informal, less frequent and incomprehensive. This is why nursing staffs' PR practice needs to be more standardized to improve, as found in this study. Additionally, nursing assistants' practice of PR was poorer than that of nurses. Nursing assistants usually received less education and lacked professional care-taking skills, whereas, PR requires a wealth of knowledge and experience. Moreover, single-restraint education showed less significant impacts on practice. ${ }^{51}$ Therefore, understanding the drivers of restraint based on TPB would be valuable in reducing restraint use and designing regular, formal, planned and systems education for nursing staff, especially for nursing assistants.

Consistent with other publications, the high mean score in behavioral intention revealed that nursing staff highly 


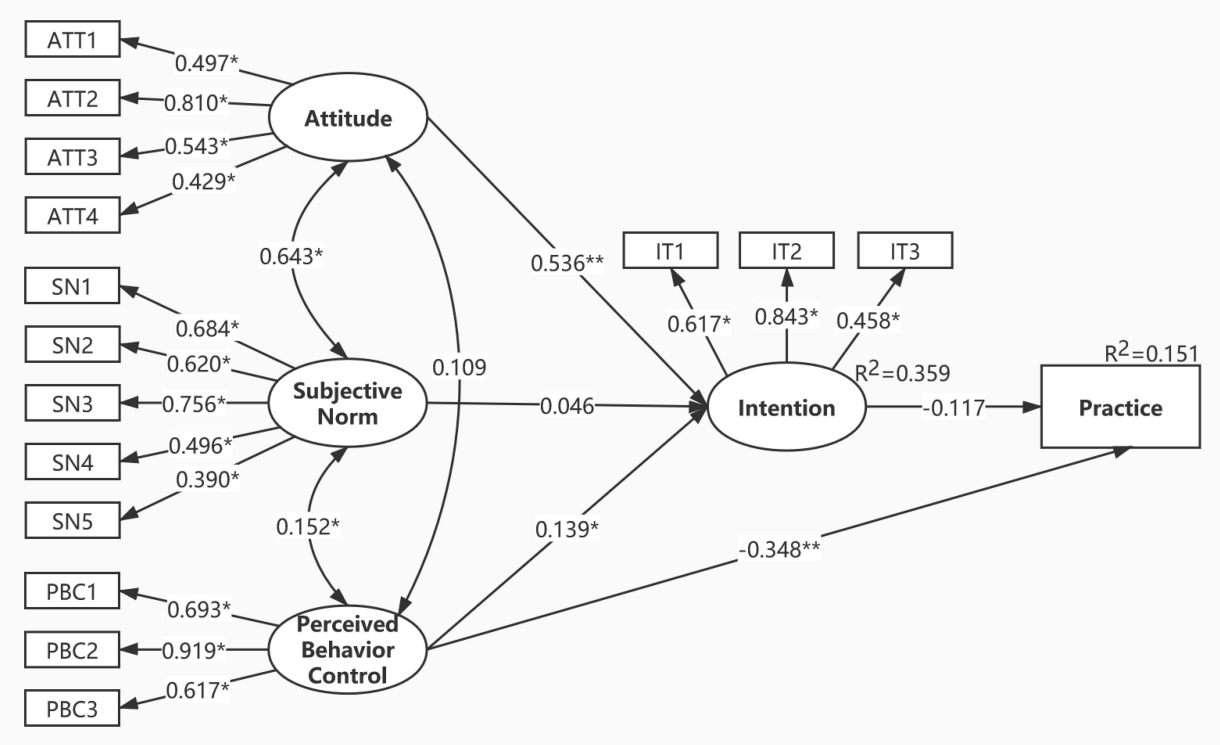

Figure 2 Structural equation model for the intention and practice of nursing staff toward the physical restraint use with Standard regression weigh. Notes: $* * p<0.001, * P<0.05$.

Abbreviations: ATT, attitude; SN, subjective norm; PBC, perceived behavioral control; IT, intention.

intend to use PR on older adults. ${ }^{26,27}$ The nursing staffs' intention on older adults who require feeding tubes and are undergoing high fall risk ranked highest, which coincided with the finding that prevention of falls and extubation are common reasons for using PR. ${ }^{15}$ A systematic review showed that PR could not be an effective measure to reduce falls and injuries, as the risk of falling increased..$^{10}$ Nevertheless, the nursing staff still regarded PR as an important measure to reduce falls and prevent injuries. That indicates that evidence-based education needs to be frequently updated, and new ideas and information need to be supported to promote change in behavioral intentions.

The study demonstrated that nursing staff had a positive attitude toward using PR on older adults, which was similar to the study of Mayerl et al. ${ }^{52}$ A systematic review of qualitative and quantitative studies showed that nursing staff would experience negative feelings toward practicing PR on older adults. ${ }^{53}$ A previously conducted qualitative study also showed that positive and negative attitudes toward PR coexist in practice. $^{22}$ However, these negative attitudes seeming did not help

Table 4 Total, Direct, and Indirect Effects of Variables in the SEM

\begin{tabular}{|l|c|c|c|}
\hline Pathway & Total Effect & Direct Effect & Indirect Effect \\
\hline Attitude $\rightarrow$ Intention & 0.536 & $0.536^{* *}$ & - \\
\hline SN $\rightarrow$ Intention & 0.046 & 0.046 & - \\
\hline PBC $\rightarrow$ Intention & 0.139 & $0.139 *$ & - \\
\hline Intention $\rightarrow$ Practice & -0.117 & $-0.117^{*}$ & -0.063 \\
\hline Attitude $\rightarrow$ Practice & -0.063 & - & -0.005 \\
\hline SN $\rightarrow$ Practice & -0.005 & - & -0.016 \\
\hline PBC $\rightarrow$ Practice & -0.364 & $-0.348 *$ & \\
\hline
\end{tabular}

Notes: $* * P<0.001, * P<0.05$.

Abbreviations: SN, subjective norm; PBC, perceived behavioral control. 
staff to reduce the use of PR. Although the side effects of using PR were well known to the nursing staff, they still chose to use PR in clinical practice for various reasons. The majority thought PR protected older adults' safety, and it is safe or beneficial. Several factors such as moral conflicts, absence of professional decision-making guidelines and insufficient knowledge have contributed to this attitude in actual practice. ${ }^{54,55}$ Furthermore, a cultural atmosphere of seeing PR as an "ordinary" care measure has formed in the past few decades and staffs' attitudes seem to be hard to change. ${ }^{56}$ Thus, as Hamers et al suggested, a more targeted intervention combined with a cultural context should be considered to reduce PR use in LTC facilities. ${ }^{57}$

Nursing staff experienced internal and external social pressure when using PR on older adults. They believed that other co-workers, doctors, nursing administrators would approve them of using PR. Though abuse of PR gets regulated to a certain extent due to the probable opposition from the older adults and their families. ${ }^{23}$ Studies have shown that the participation of family members can reduce the use of PR. ${ }^{18,19}$ On the contrary, some studies showed that older adults experienced an increased risk of PR use due to permission and informed consent signed by family members. ${ }^{16,58}$ This might be because the permission of older adults and their relatives for PR use could alleviate the moral or responsible pressure of nursing staff. PBC with an intermediate score illustrated modest control of the situation and that the decision was not taken easily. There is a lack of studies concentrating on PBC of nursing staffs' PR practices in LTC facilities. A study by Via-Clavero et al among ICU nurses also found that their PBC to use PR in intubated patients was above the mid-scale in ICU. ${ }^{27}$ Confidence in their ability to use PR in PBC scored the lowest, which could be explained by the lack of regulations and policies to guide PR use in LTC facilities. Else, nursing assistants reported higher self-efficacy and ease of PR use. As reported, high self-efficacy to use PR could be a considerable barrier in adopting restraintreduction interventions or following the clinical guidelines. ${ }^{59}$

\section{Predictors of Behavioral Intention}

The findings showed that attitude was the strongest predicting factor for behavioral intention, followed by PBC. $\mathrm{SN}$ was non-significant. These results were different from a previous study that stated nurses' intention to use PR on
ICU intubated patients could be explained by three standard elements of TPB. ${ }^{28}$ This is in line with the assumption that the effect of each variable of TPB on behavioral intention varies across settings, behaviors and samples. ${ }^{37}$

Attitude showed a direct correlation between positive attitude and intention to use PR. This is consistent with previous studies. ${ }^{24}$ Attitude, as the strongest motivating factor, implies that nursing staffs' intention toward PR is almost completely up to the evaluation (positive or negative) of practice. The perception of potential barriers in clinical practice, ie, PBC was a vital predictor of intention. The implementation process of PR faces more challenges as there are no standardized laws and regulations on PR use in Chinese LTC facilities. Therefore, the nursing staffs' ability and confidence to practice is inevitably affected by various environmental factors. Interestingly, SN was not a significant predictor in the model despite showing a positive correlation with intention. It was regarded as the weakest or most insignificant predictor in many TPB and health-related behavior studies, similar to the results of this study. ${ }^{60}$ This may be because the decision to use PR in these facilities is usually made by nurses or nursing assistants themselves, without including doctors or family members in the decision-making process. Hence, the nursing staffs' intention is not easily influenced by other social referents. ${ }^{16}$ Empirically, the same information could affect behavioral, normative, and/or control beliefs, which are the theoretical antecedents of attitude, SN, and PBC, respectively. As per our study, SN reported highly significant associations with attitude and $\mathrm{PBC}$ in the SEM, statistically, this may weaken the direct effect on intention. Also, using direct measures for attitude and PBC, but indirect beliefs for SN may intensify the results. Although reflective ("direct") measures of attitude, SN and PBC are sufficient to predict intention and practice, future studies may be conducted to consider behavioral and control beliefs and explore their effects on intention and practice in-depth. Importantly, SN was noted as a narrow conception, focusing only on what important people think others should do, but ignoring what they themselves do descriptive norms. ${ }^{36,61}$ The predictive role of descriptive norms on intention in TPB was evidenced in a meta-analysis. ${ }^{62}$ A lack of descriptive norms could also be another considered a reason for $\mathrm{SN}$ not being a significant predictor. Further study is recommended to test this viewpoint. 


\section{Predictors of Nursing Practice}

Based on TPB, an antecedent factor for leading to behavior is behavioral intention, and its predictive success has been explained in many publications. ${ }^{36,63}$ However, this study showed that the nursing practice of PR use was not significantly predicted by the intention of nursing staff in LTC facilities. Interpretation of this result requires caution. Practice subscale of another validated questionnaire was used to assess nursing practice regarding PR use because of the following considerations: (a) We are interested in the practice process of using PR, that is, a category of behaviors (eg evaluate, implement, record, remove, etc.), not a single action; (b) It is hard to simultaneously measure intention and practice toward PR as its use varies on different conditions and no independent evidence suggest the high temporal stability of the practice toward PR use. This may lead to the assessment of intention and practice are incompatible in terms of tools used, which probably was the main reason for the insignificant pathway from intention to practice. Furthermore, not all high intention could always be translated into performing a behavior, and it may depend on how simple or complicated the behavior is. ${ }^{64}$ As we know, the practice process of using PR is so complex. Intention and practice of nursing staff were measured at different times, the intention reflected the subjective probability of future use, but the practice was the past actual practice in the process of implementing the behavior, which could be another reason for the insignificance of intention to practice. ${ }^{65}$ A previous study reported nurses' practice to use PR was influenced by their intention. ${ }^{24}$ Intentions exert a much less significant effect if the nursing staff could not perceive clear needs to using PR and the overuse of PR is related to the knowledge and capacity of the nursing staff. ${ }^{52}$ Unlike nurses in hospitals, over three-quarters of the samples in our study were nursing assistants who were characterized by insufficient knowledge and skills. This was found to influence the results of practice.

The significant predictor of practice to use PR in this study was PBC. This was supported by previous studies of other behaviors. ${ }^{60}$ Nursing staff who stated high confidence and ease in the decision-making of PR use found it easy to perform negative PR practice. Probably because LTC facilities in China have formed a cultural atmosphere where PR is used as a routine care measure to protect the safety of older adults. Also, there are currently no relevant norms, laws and regulations to guide and manage the use of PR, so that nursing staff thinks their practice is correct. Studies reported that lack of time, resources and education are the main barriers to restraint reduction. ${ }^{54,66}$ Thus, providing nursing staff with the skills and knowledge for PR use should be a targeted measure for promoting their practice.

\section{Advantages and Limitations}

This study applied the SEM approach to testing a theoretical framework based on TPB. This helped us determine the path and extent of underlying factors associated with the nursing practice toward the use of PR in LTC facilities. To our knowledge, this is an important step forward in the research on PR practice in Chinese LTC facilities, as it provided fundamental evidence for developing effective restraint-reduction programs. The current study does have several limitations as well. First, a convenience sample of the nursing staff was taken from LTC facilities in just one province (Chongqing) of China to conduct the study. Hence, we should be cautious about generalizing the findings of this study. However, the findings should be similar throughout China, given that these types of LTC facilities operate under similar quality management, and the allocation of nursing human resources has similar characteristics. Second, a cross-sectional study cannot define causality among variables as well as a longitudinal study can. Prospective studies may be conducted to develop interventions based on predictive factors and to explore the occurrence mechanism of nursing staffs' practice of PR in LTC facilities. Third, the measurements in this study, although there were various explanation and literature support, which can limit the findings by (a) lack of descriptive norms in the TPB, (b) the use of direct measures for attitude and $\mathrm{PBC}$, but indirect beliefs for $\mathrm{SN}$, (c) incompatibility between practice and TPB constructs in terms of measurement used. Whether these factors exert effects on intention and practice should be explored further in future studies.

\section{Conclusion}

Regarding PR use in LTC facilities, the nursing staff holds a positive attitude, experiences social pressure, perceives modest behavioral control and highly intends to use it. Meanwhile, the practice of PR reported moderate levels. TPB provided useful insight into better understanding nursing staff's practice of PR use, even though it did not support all the TPB principles. For instance, the study showed a lack of influence of $\mathrm{SN}$ upon intention and intention upon practice. Further research is needed. The campaign for restraint reduction should take a systems approach, addressing significant predictors of practice and developing targeted interventions based on TPB. 


\section{Acknowledgments}

We would like to thank all study participants for their considerable support and assistance.

\section{Disclosure}

The authors had no competing interests in this work.

\section{References}

1. Population Reference Bareau. 2020 World population data sheet shows older populations growing, total fertility rates declining; 2018. Available from: https://www.prb.org/2020-world-populationdata-sheet/. Accessed October 6, 2020.

2. National Bureau of Statistics. 2019 Statistical communique of national economic and social development of the People's Republic of China; 2020. Available from: http://www.stats.gov.cn/t $\mathrm{jsj} / \mathrm{zxfb} /$ 202002/t20200228_1728913.html. Accessed October 6, 2020.

3. Feng Z, Hirdes JP, Smith TF, et al. Use of physical restraints and antipsychotic medications in nursing homes: a cross-national study. Int $J$ Geriatr Psychiatry. 2009;24(10):1110-1118. doi:10.1002 gps. 2232

4. Xu D, Kane RL, Shippee T, Lewis TM. Identifying consistent and coherent dimensions of nursing home quality: exploratory factor analysis of quality indicators. $J$ Am Geriatr Soc. 2016;64(12):e259e264. doi:10.1111/jgs.14562

5. Bleijlevens MH, Wagner LM, Capezuti E, Hamers JP. Physical restraints: consensus of a research definition using a modified delphi technique. J Am Geriatr Soc. 2016;64(11):2307-2310. doi:10.1111/ jgs. 14435

6. Bellenger EN, Ibrahim JE, Lovell JJ, Bugeja L. The nature and extent of physical restraint-related deaths in nursing homes: a systematic review. J Aging Health. 2018;30(7):1042-1061. doi:10.1177/ 0898264317704541

7. Bellenger E, Ibrahim JE, Bugeja L, Kennedy B. Physical restraint deaths in a 13-year national cohort of nursing home residents. Age Ageing. 2017;46(4):688-693. doi:10.1093/ageing/afw246

8. Castle NG, Engberg J. The health consequences of using physical restraints in nursing homes. Med Care. 2009;47(11):1164-1173. doi:10.1097/MLR.0b013e3181b58a69

9. Smith DA. Documented, systematic and individualized communication with the attending physician for fall risk reduction/injury mitigation care planning. J Am Med Dir Assoc. 2018;19(8):714-716. doi:10.1016/j.jamda.2018.05.032

10. Tang Wing S, Chow Yeow L, Lin SKS. The effectiveness of physical restraints in reducing falls among adults in acute care hospitals and nursing homes: a systematic review. JBI Libr Syst Rev. 2012;10 (5):307-351. doi:10.11124/jbisrir-2012-4

11. Estevez-Guerra GJ, Farina-Lopez E, Nunez-Gonzalez E, GandoyCrego M, Calvo-Frances F, Capezuti EA. The use of physical restraints in long-term care in Spain: a multi-center cross-sectional study. BMC Geriatr. 2017;17(1):29. doi:10.1186/s12877-017-0421-8

12. Hofmann H, Schorro E, Haastert B, Meyer G. Use of physical restraints in nursing homes: a multicentre cross-sectional study. BMC Geriatr. 2015;15(1):129. doi:10.1186/s12877-015-0125-x

13. Heinze C, Dassen T, Grittner U. Use of physical restraints in nursing homes and hospitals and related factors: a cross-sectional study. $J \quad$ Clin Nurs. 2012;21(7-8):1033-1040. doi:10.1111/j.13652702.2011.03931.x

14. Chiba Y, Yamamoto-Mitani N, Kawasaki M. A national survey of the use of physical restraint in long-term care hospitals in Japan. J Clin Nurs. 2012;21(9-10):1314-1326. doi:10.1111/j.1365-2702.20 11.03971.x
15. Hofmann H, Hahn S. Characteristics of nursing home residents and physical restraint: a systematic literature review. J Clin Nurs. 2014;23 (21-22):3012-3024. doi:10.1111/jocn.12384

16. Wang J, Liu W, Peng D, Xiao M, Zhao Q. The use of physical restraints in Chinese long-term care facilities and its risk factors: an observational and cross sectional study. $J$ Adv Nurs. 2020;76 (10):2597-2609. doi:10.1111/jan.14486

17. Staggs VS, Olds DM, Cramer E, Shorr RI. Nursing skill mix, nurse staffing level, and physical restraint use in US hospitals: a longitudinal study. $J$ Gen Intern Med. 2017;32(1):35-41. doi:10.1007/s11606-016-3830-z

18. Bollig G, Schmidt G, Rosland JH, Heller A. Ethical challenges in nursing homes - staff's opinions and experiences with systematic ethics meetings with participation of residents' relatives. Scand J Caring Sci. 2015;29(4):810-823. doi:10.1111/scs.12213

19. Gagnon MP, Desmartis M, Dipankui MT, Gagnon J, St-Pierre M. Alternatives to seclusion and restraint in psychiatry and in long-term care facilities for the elderly: perspectives of service users and family members. Patient. 2013;6(4):269-280. doi:10.1007/s40271-013-0023-2

20. Scheepmans K, Milisen K, Vanbrabant K, Paquay L, Van Gansbeke H, Dierckx de Casterlé B. Factors associated with use of restraints on older adults with home care: a secondary analysis of a cross-sectional survey study. Int J Nurs Stud. 2019;89:39-45. doi:10.1016/j.ijnurstu.2018.07.019

21. Sheng X, Zhu X, Pang X, Wang M, Yin X, Jiang Y. ICU nurses' decision-making in physical restraint use: a qualitative study. $J$ Nurs Sci. 2019;34(04):42-46. doi:10.3870/j.issn.1001-4152.2019.04.042

22. Wang J, Liu W, Xiao M, Zhao Q. A qualitative study on practice of nursing staff toward physical restraint use in elder-care institutions based on the theory of planned behavior. J Nurs Sci. 2021;36 (02):64-67. doi:10.3870/j.issn.1001-4152.2021.02.064

23. Gjerberg E, Lillemoen L, Pedersen R, Forde R. Coercion in nursing homes: perspectives of patients and relatives. Nurs Ethics. 2016;23 (3):253-264. doi:10.1177/0969733014564907

24. Eskandari F, Abdullah KL, Zainal NZ, Wong LP. Use of physical restraint: nurses' knowledge, attitude, intention and practice and influencing factors. $J$ Clin Nurs. 2017;26(23-24):4479-4488. doi:10.1111/jocn. 13778

25. Via-Clavero G, Sanjuan-Navais M, Romero-Garcia M, et al. Eliciting critical care nurses' beliefs regarding physical restraint use. Nurs Ethics. 2019;26(5):1458-1472. doi:10.1177/0969733017752547

26. Werner P, Mendelsson G. Nursing staff members' intentions to use physical restraints with older people: testing the theory of reasoned action. $J A d v$ Nurs. 2001;35(5):784-791. doi:10.1046/j.1365-2648.2001.01911.x

27. Via-Clavero G, Guardia-Olmos J, Gallart-Vive E, Arias-Rivera S, Castanera-Duro A, Delgado-Hito P. Development and initial validation of a theory of planned behaviour questionnaire to assess critical care nurses' intention to use physical restraints. $J$ Adv Nurs. 2019;75 (9):2036-2049. doi:10.1111/jan.14046

28. Via-Clavero G, Guàrdia-Olmos J, Falcó-Pegueroles A, et al. Factors influencing critical care nurses' intentions to use physical restraints adopting the theory of planned behaviour: a cross-sectional multicentre study. Aust Crit Care. 2020;33(5):426-435. doi:10.1016/j.aucc.2019.09.003

29. Ajzen. I. The theory of planned behavior. Organ Behav Hum Decis Process. 1991;50(2):179-211. doi:10.1016/0749-5978(91)90020-T

30. Zhou H, Romero SB, Qin X. An extension of the theory of planned behavior to predict pedestrians' violating crossing behavior using structural equation modeling. Accid Anal Prev. 2016;95(Pt B):417-424. doi:10.1016/j.aap.2015.09.009

31. Angelis A, Pancani L, Steca P, et al. Testing an explanatory model of nurses' intention to report adverse drug reactions in hospital settings. J Nurs Manag. 2017;25(4):307-317. doi:10.1111/jonm.12467

32. Strong C, Lin CY, Jalilolghadr S, Updegraff JA, Broström A, Pakpour AH. Sleep hygiene behaviours in Iranian adolescents: an application of the theory of planned behavior. J Sleep Res. 2018;27 (1):23-31. doi:10.1111/jsr.12566 
33. Mirzaei N, Dehdari T, Taghdisi MH, Zare N. Development of an instrument based on the theory of planned behavior variables to measure factors influencing Iranian adults' intention to quit waterpipe tobacco smoking. Psychol Res Behav Manag. 2019;12:901-912. doi:10.2147/PRBM.S196417

34. Kopke S, Muhlhauser I, Gerlach A, et al. Effect of a guideline-based multicomponent intervention on use of physical restraints in nursing homes: a randomized controlled trial. JAMA. 2012;307 (20):2177-2184. doi:10.1001/jama.2012.4517

35. Galaviz KI, Jauregui-Ulloa E, Fabrigar LR, Latimer-Cheung A, Lopez y Taylor J, Lévesque L. Physical activity prescription among Mexican physicians: a structural equation analysis of the theory of planned behaviour. Int $J$ Clin Pract. 2015;69(3):375-383. doi:10.1111/ijcp.12546

36. Åstrøm AN, Lie SA, Gülcan F. Applying the theory of planned behavior to self-report dental attendance in Norwegian adults through structural equation modelling approach. BMC Oral Health. 2018;18 (1):95. doi:10.1186/s12903-018-0558-7

37. Ajzen I, Fishbein M. The influence of attitudes on behavior. In: Albarracín BTJD, Zanna MP, editors. The Handbook of Attitudes. Mahwah, NJ, USA: Lawrence Erlbaum; 2005:173-221.

38. Wang J, Liu WC, Zhao QH, Xiao MZ. Bibliometric analysis of the studies on physical restraints in nursing homes. J Nurs Train. 2020;35 (13):1158-1163. doi:10.16821/j.cnki.hsjx.2020.13.002

39. Kendall MG, Stuart A, Ord JK. Kendall's advanced theory of statistics. v. 1: distribution theory. Technometrics. 1994;31(1):128.

40. Ajzen I. Constructing a theory of planned behavior questionnaire; 2006. Available from: http://www.people.umass.edu/aizen/tpb.htm. Accessed October 6, 2020.

41. Haut A, Kolbe N, Strupeit S, Mayer H, Meyer G. Attitudes of relatives of nursing home residents toward physical restraints. $J \quad$ Nurs Scholarsh. 2010;42(4):448-456. doi:10.1111/j.15475069.2010.01341.x

42. Zhu G, Qian X, Qi L, et al. The intention to undertake physical activity in pregnant women using the theory of planned behaviour. $J$ Adv Nurs. 2020;76(7):1647-1657. doi:10.1111/jan.14347

43. Shi JZ, Mo XK, Sun ZQ. Content validity index in scale development. J Cent South Univ. 2012;37(02):49-52. doi:10.3969/j. issn.1672-7374.2002.02.07

44. Zhou D. Detailed Explanations of Statistical Analysis and Graphical Expression Examples in Clinical Medical Research. Beijing, China. Beijing Science and Technology Press; 2018:331-363.

45. Zheng R, Sun D. Psychometric validation. Beijing, China. Renmin University of China Press; 2013: 67-109.

46. Suen KPL. Knowledge, attitude and practice of nursing home staff towards physical restraints in Hong Kong nursing homes. Asian J Nurs Stud. 1999;05(02):73-86.

47. Steiger JH. Understanding the limitations of global fit assessment in structural equation modeling. Pers Individ Dif. 2007;42(5):893-898. doi:10.1016/j.paid.2006.09.017

48. Maccallum RC, Browne MW, Sugawara HM. Power analysis and determination of sample size for covariance structure modeling. Psychol Methods. 1996;1(2):130-149. doi:10.1037/1082-989X.1.2.130

49. Kor PP, Kwan RYC, Liu JY, Lai C. Knowledge, practice, and attitude of nursing home staff toward the use of physical restraint: have they changed over time? J Nurs Scholarsh. 2018;50(5):502-512. doi:10.1111/jnu.12415

50. Karagozoglu S, Ozden D, Yildiz FT. Knowledge, attitudes, and practices of Turkish intern nurses regarding physical restraints. Clin Nurse Spec. 2013;27(5):262-271. doi:10.1097/NUR.0b013 e3182a0baec
51. Lan SH, Lu LC, Lan SJ, et al. Educational intervention on physical restraint use in long-term care facilities - systematic review and meta-analysis. Kaohsiung J Med Sci. 2017;33(8):411-421. doi:10.1016/j.kjms.2017.05.012

52. Mayerl H, Trummer T, Stolz E, Rásky É, Freidl W. Nursing professionals' attitudes toward use of physical restraints in Styrian nursing homes (Austria). Pflege. 2019;32(1):57-63. doi:10.1024/1012-5302/ a000649

53. Mohler R, Meyer G. Attitudes of nurses towards the use of physical restraints in geriatric care: a systematic review of qualitative and quantitative studies. Int $J$ Nurs Stud. 2014;51(2):274-288. doi:10.1016/j.ijnurstu.2013.10.004

54. Kong EH, Choi H, Evans LK. Staff perceptions of barriers to physical restraint-reduction in long-term care: a meta-synthesis. $J$ Clin Nurs. 2017;26(1-2):49-60. doi:10.1111/jocn.13418

55. Goethals S, Dierckx de Casterlé B, Gastmans C. Nurses' decisionmaking in cases of physical restraint: a synthesis of qualitative evidence. $J$ Adv Nurs. 2012;68(6):1198-1210. doi:10.1111/j.13652648.2011.05909.x

56. Farina-Lopez E, Estevez-Guerra GJ, Gandoy-Crego M, Polo-Luque LM, Gomez-Cantorna C, Capezuti EA. Perception of Spanish nursing staff on the use of physical restraints. J Nurs Scholarsh. 2014;46 (5):322-330. doi:10.1111/jnu.12087

57. Hamers JP, Meyer G, Kopke S, Lindenmann R, Groven R, Huizing AR. Attitudes of Dutch, German and Swiss nursing staff towards physical restraint use in nursing home residents, a cross-sectional study. Int $J$ Nurs Stud. 2009;46(2):248-255. doi:10.1016/j.ijnurstu.2008.06.007

58. Huang HC, Huang YT, Lin KC, Kuo YF. Risk factors associated with physical restraints in residential aged care facilities: a community-based epidemiological survey in Taiwan. $J$ Adv Nurs. 2014;70(1):130-143. doi:10.1111/jan.12176

59. Kortteisto T, Kaila M, Komulainen J, Mäntyranta T, Rissanen P. Healthcare professionals' intentions to use clinical guidelines: a survey using the theory of planned behaviour. Implement Sci. 2010;5(1):51. doi:10.1186/1748-5908-5-51

60. Amin M, Elyasi M, Bohlouli B, ElSalhy M. Application of the theory of planned behavior to predict dental attendance and caries experience among children of newcomers. Int J Environ Res Public Health. 2019;16(19):3661. doi:10.3390/ijerph16193661

61. Sieverding M, Matterne U, Ciccarello L. What role do social norms play in the context of men's cancer screening intention and behavior? Application of an extended theory of planned behavior. Health Psychol. 2010;29(1):72-81. doi:10.1037/a0016941

62. Rivis A, Sheeran P. Descriptive norms as an additional predictor in the theory of planned behaviour: a meta-analysis. Curr Psychol. 2003;22(3):218-233. doi:10.1007/s12144-003-1018-2

63. Ko NY, Feng MC, Chiu DY, Wu MH, Feng JY, Pan SM. Applying theory of planned behavior to predict nurses' intention and volunteering to care for SARS patients in southern Taiwan. Kaohsiung J Med Sci. 2004;20(8):389-398. doi:10.1016/S1607-551X(09)70175-5

64. Ajzen I. The theory of planned behaviour: reactions and reflections. Psychol Health. 2011;26(9):1113-1127. doi:10.1080/ 08870446.2011.613995

65. Mceachan RRC, Conner M, Taylor NJ, Lawton RJ. Prospective prediction of health-related behaviours with the theory of planned behaviour: a meta-analysis. Health Psychol Rev. 2011;5(2):97-144. doi:10.1080/17437199.2010.521684

66. Eun-Hi K, Lois KE. Nursing staff views of barriers to physical restraint reduction in nursing homes. Asian Nurs Res. 2012;6 (4):173-180. doi:10.1016/j.anr.2012.10.007 


\section{Publish your work in this journal}

Psychology Research and Behavior Management is an international, peer-reviewed, open access journal focusing on the science of psychology and its application in behavior management to develop improved outcomes in the clinical, educational, sports and business arenas. Specific topics covered in the journal include: Neuroscience, memory and decision making; Behavior modification and management; Clinical

applications; Business and sports performance management; Social and developmental studies; Animal studies. The manuscript management system is completely online and includes a very quick and fair peer-review system, which is all easy to use. Visit http://www. dovepress.com/testimonials.php to read real quotes from published authors. 